\title{
SUBJETIVIDADES
}

\section{Estudo Teórico}

e-ISSN: 2359-0777

\section{ANGÚSTIA $E$ CONSTITUIÇÃO SUBJETIVA: DO OBJETO NÃO SIGNIFICANTIZÁVEL AO SIGNIFICANTE \\ Anxiety and Subjective Constitution: From the Unsignificable Object to the Signifier}

Angustia y Constitución Subjetiva: Del Objeto no Significantizable al Significante

Angoisse et Constitution Subjective: De L'objet non Sigficantisé au Signifiant

DOI: $10.5020 / 23590777.16 .2 .60-70$

\section{Ariana Lucero (Lattes)}

Psicóloga, psicanalista. Mestre e Doutora em Psicologia pela UFMG (área de concentração: Estudos Psicanalíticos). Pós-doutoranda do Programa de Psicologia Institucional da UFES; bolsista da CAPES/FAPES.

\section{Angela Maria Resende Vorcaro (Lattes)}

Psicanalista. Doutora em Psicologia Clínica pela PUC-SP. Professora do Departamento de Psicologia da UFMG. Membro da ALI. Autora dos livros Crianças na psicanálise (1999) e A criança na clínica psicanalítica (2004).

\section{Resumo}

O presente artigo tem por objetivo mostrar como a incidência do significante na estruturação do sujeito, tal como definido por Jacques Lacan, é concomitante a uma perda do corpo vivo. Para tanto, abordaremos a transformação que se opera no sistema conceitual lacaniano a partir do seminário sobre a angústia: do corpo do estágio do espelho ao corpo restituído às suas particularidades anatômicas. Nesse percurso, mostraremos como o traço unário se coloca como uma marca corporal que antecede o significante, já que este necessita de três tempos para ser assimilado. Ademais, trataremos da extração do objeto $a$ e sua relação com a angústia na medida em que o afeto se coloca como causa da perda, e não como efeito da castração. Interessa-nos apontar para a presença do objeto em certo momento da constituição subjetiva em que teríamos apenas as pulsões não integradas na imagem especular. Esses objetos pulsionais, que visam apenas o gozo, coexistem independentemente de qualquer organização ou cronologia, não são socializados ou partilháveis pela cultura. Assim, interrogamos a existência desses objetos não significantizáveis lado a lado aos objetos revestidos pela função fálica. O falo como significante da perda do objeto sinaliza o desejo. Porém algo subsiste para além do desejo, produzindo angústia e requerendo novos arranjos subjetivos e pulsionais.

Palavras-chave: angústia; objeto $a$; constituição subjetiva; traço unário; significante.

\section{Abstract}

The present article aims to show how the incidence of the significant in the structuring of the subject, as defined by Jacques Lacan, is concomitant to a loss of the living body. To do so, we will approach the transformation that takes place in the Lacanian conceptual system from the seminar on anguish: from the body of the mirror stage to the body restored to its anatomical particularities. In this course, we will show how the unary trace is placed as a body mark that precedes the significant, since it requires three times to be assimilated. In addition, we will deal with the extraction of the object " $a$ " and its relation to the anguish, insofar as this affection becomes the cause of the loss, and not as the effect of castration. We are interested in pointing to the presence of the object at a certain moment of the subjective constitution in which we would have only the pulses not integrated in the mirror image. These instinctual objects, which aim only at enjoyment, coexist independently of any organization or chronology, are not socialized or shareable by culture. Thus, we question the existence of these nonsignifiable objects side by side with the objects covered by the phallic function. The phallus as a signifier of the object loss signals desire. 
However, something subsists beyond desire, producing anguish and requiring new subjective and instinctual arrangements.

Keywords: anguish; object " a"; subjective constitution; unary trace; significant.

\section{Resumen}

Este artículo tiene el objetivo de enseñar cómo la incidencia del significante en la estructuración del sujeto, como definido por Jacques Lacan, es concomitante a una pérdida del cuerpo vivo. Por lo tanto, hablaremos de la transformación que opera en El sistema conceptual lacaniano a partir del seminario acerca de la angustia: del cuerpo de la etapa del espejo al cuerpo restituido a sus particularidades anatómicas. En este sentido, enseñaremos cómo un punto unario se pone como marca corporal que antecede el significante, ya que se necesita a tres tiempos para ser asimilado. Además, trataremos de extracción del objeto a y su relación con la angustia, a medida que su afectos y pone como causa de pérdida, y no como efecto de la castración. Nos interesa indicar para la presencia del objeto en cierto momento de la constitución subjetiva en que tendríamos solo las pulsiones no integradas en la imagen especular. Estos objetos pulsionales, que buscan solo el gozo, coexisten independientemente de cualquier organización o cronología, no son socializados o de compartir por la cultura. Así, interrogamos la existencia de estos objetos no "significantizables" hombro a hombro a los objetos revestidos por la función fálica. El falo como significante de la pérdida del objeto señaliza el deseo. Pero, algo subsiste más allá del deseo, produciendo angustias y que requiere nuevos arreglos subjetivos y pulsionales.

Palabras clave: angustia; objeto a; constitución subjetiva; punto unario; significante.

\section{Résumé}

Cet article vise à montrer comment l'incidence du signifiant dans la structuration du sujet, tel que défini par Jacques Lacan, est concomitante à une perte de l'organisme vivant. Ainsi, nous discutons la transformation qui fonctionne dans le système conceptuel lacanien à partir du séminaire sur l'angoisse: du corps dans le stade du miroir au corps restitué à ses particularités anatomiques. Dans ce parcours, nous montrons comment le trait unaire se pose comme une empreinte corporel qui précède le signifiant, car il nécessite de trois temps pour être assimilé. En outre, nous abordons l'extraction de l'objet a et son rapport à l'angoisse, dans la mesure que cette affection est posée comme une cause de la perte, et pas comme l'effet de la castration. Ce que nous intèresse de signaler est la présence de l'objet à un certain moment de la constitution subjective quand il n n'aurait que les pulsions non integrées dans l'image miroir. Ces objets pulsionnels, qui visent uniquement à la jouissance coexistent indépendamment de n'importe quel organisation ou chronologie, ne sont pas socialisés ou partageables par la culture. Ainsi, nous interrogeons l'existence de ces objets non signifiables côte à côte des objets couverts par la fonction phallique. Le phallus comme signifiant de la perte de l'objet signale le désir. Mais il reste quelque chose au delà du désir, en produisant de l'angoisse et en demandant des nouveaux arrangements subjectifs et instinctifs.

Mots-clés: angoisse; objet a; constitution subjective; trait unaire; signifiant.

O presente artigo tem por objetivo mostrar como a incidência do significante na estruturação do sujeito, tal como definido por Jacques Lacan, é concomitante a uma perda do corpo vivo. Trata-se de responder à questão posta no seminário sobre a angústia: “Como é que o sujeito entrou nessa história de significante?” (Lacan, 1962-63/2005, p. 79). Ou, em outros termos, "o problema está na entrada do significante no real e em ver como disso nasce o sujeito" (Lacan, 1962-63/2005, p. 100). Para tanto, servir-nos-emos das teorizações produzidas no Seminário 10, tomado por muitos comentadores como ponto de virada do pensamento lacaniano.

Jacques-Alain Miller (2005, pp. 34-35), por exemplo, enfatiza uma radical mudança de coordenadas no ensino lacaniano no seminário sobre a angústia, com a passagem de um sistema conceitual a outro: do corpo do estágio do espelho ao corpo restituído às suas particularidades anatômicas. De forma um pouco diferente, Colette Soler (2012) pode dizer que o seminário sobre a angústia é, na verdade, um seminário sobre o objeto: “Trata-se aqui, de fato, dos primeiros passos na elaboração do objeto $a$ " (p. 18). Ora, como o objeto adquire um papel essencial nessa mudança de perspectiva a respeito do corpo? Qual seria sua relação com o significante? E por que a angústia é o afeto eleito por Lacan para fazer a junção do corpo com o significante? 


\section{Traço Unário, Gozo e Significante}

No Seminário 10, Lacan, (1962-63/2005) sublinha o fato de que, quando colocada na frente de um espelho, a criança se volta para o Outro que está atrás dela, oferecendo-lhe o suporte para que ela se veja: "Através desse movimento de virada de cabeça, que se volta para o adulto, como que para invocar seu assentimento, e depois retorna à imagem, ela parece pedir a quem a carrega, e que representa aqui o grande Outro, que ratifique o valor dessa imagem" (p. 41). Desde o Seminário 8 , com efeito, o psicanalista já destacava o olhar do Outro como instituidor do traço unário:

Este olhar do Outro, devemos concebê-lo como sendo interiorizado por um signo. Isso basta. Ein einziger Zug [um traço unário]. Não há necessidade de todo um campo de organização e de uma introjeção maciça. Este ponto, grande I, do traço único, este signo do assentimento do Outro, da escolha de amor sobre a qual o sujeito pode operar, está ali em algum lugar e se regula na continuação do jogo do espelho. Basta que o sujeito vá coincidir ali em sua relação com o Outro para que este pequeno signo, este einziger Zug, esteja à sua disposição. (Lacan, 1960-61/1992, p. 344)

O conceito de traço unário aparece logo no início de nossa argumentação para mostrar que, desde os primeiros tempos da constituição subjetiva, há algo que vem do Outro, mas que não é passível de ser significantizado pelo sujeito.

Durante todo seu ensino, Lacan (1962-63/2005) parte do princípio, amiúde reiterado, de que o grande Outro é anterior a tudo o que podemos elaborar ou compreender. O mundo existe, está dado e o sujeito só pode surgir a partir desse Outro, lugar do tesouro dos significantes, que lhe é anterior e constitutivo (Lacan, 1962-63/2005, p. 179). O significante vem do Outro e a primeira coisa que sua emergência implica é o apagamento da relação do signo com a coisa: A palavra é a morte da coisa e as experiências das quais o traço era a marca serão para sempre esquecidas, recalcadas, em virtude do advento do significante. Vejamos se a analogia que Lacan sugere para o conceito de traço unário, baseando-se na história de Robinson Crusoé, de Daniel Defoe ${ }^{1}$, pode nos ajudar a esclarecer o que se passa no advento do sujeito pelo significante.

Há uma passagem do livro de Defoe que relata o momento em que o protagonista - Robinson Crusoé - depara-se com a marca de um pé descalço na praia em que se acreditava sozinho. Surpreso e inquieto, refletindo sobre a possível presença de outros humanos na ilha, Robinson volta após alguns dias ao local onde encontrou a pegada para compará-la com seu próprio pé. Verifica, então, que se tratava de um pé menor que o dele (Defoe, 2009, p. 189 e p. 195). Lacan, (1961-62/2003) supõe uma situação, ausente da narrativa de Defoe (2009) (a despeito das indicações lacanianas), em que, para conferir se está mesmo sozinho na ilha, Robinson assinala o lugar das pegadas com um pauzinho e apaga seu registro da areia para saber se a suposta pessoa passará por ali novamente. Cabe destacar que Robinson é o único que sabe para que servem os pauzinhos, e, enquanto efetua esta ação, toma o cuidado de apagar seu próprio rastro: "Se o rastro é apagado, o sujeito cerca o lugar por um cerne, algo que desde então lhe concerne, ele, a referência a partir do lugar onde ele encontrou o rastro, vocês têm aí o nascimento do significante" (Lacan, 1961-62/2003, p. 136).

Nosso autor caracteriza o traço unário como esse cerne, que em francês é usado para designar o roxo do hematoma resultante do efeito de uma pancada; um círculo em tom de marrom ao redor dos olhos, que poderia caracterizar as olheiras; o traçado deixado em um tecido por uma mancha mal removida; um dos círculos concêntricos do tronco da árvore (Le Petit Robert, 2014, p. 383). Este último significado é o que mais se aproxima da definição literal de cerne em português: parte interna do tronco das árvores, formada por células mortas, em que não ocorre o transporte de água, geralmente de cor escura (Dicionário Houaiss, 2009, p. 44). Nas definições em francês predomina a ideia de um borrão, de algo que tem uma cor escura e se esparrama em torno de alguma outra coisa, indicando que algo se passou ali. Imaginemos que, para apagar a pegada na areia, Robinson teve que esparramá-la ao redor da marca.

O significante pode ser uma marca, um rastro, um pauzinho, uma escrita, um traço unário, porém nunca é possível lêlo sozinho. Lembremos que um significante só representa um sujeito para outro significante. O processo de identificação comporta o retorno da demarcação (do significante) sobre a marca, sobre o traço unário, incluindo sua rasura. A identificação já é um processo de significantização de algumas marcas que não podem ser ignoradas, pois demoram um tempo para sair e nunca se apagam completamente. O significante vem no lugar da experiência, ofuscando-a e demarcando o que aconteceu, ao fazer referência a outro significante. Não pode haver articulação de um significante sem esses três tempos: a marca, seu contorno e o apagamento da marca - "uma vez constituído o significante, há dois outros [tempos] antes" (Lacan, 1961-62/2003, pp. 136-137).

Com efeito, a pegada de Sexta-Feira, seu passo (pas em francês), nos remete ao comentário de Lacan (1961-62/2003) sobre a negação. Como lembram Silveira e Vorcaro (2016), Lacan partira de construções gramaticais para situar os efeitos do não considerando o que Freud (1925/2007) indica: a negação é a admissão de uma representação inconsciente na consciência.

1 Cf. Defoe, D. (2009). Robinson Crusoé. Rio de Janeiro: BestBolso. 
Sublinhando a função das partículas componentes da negação na língua francesa - o ne discordancial e o pas exclusivo, assim ressaltados por Pichon (1928) ${ }^{2}$ - Lacan (1961-62/2003) salienta a distinção entre o sujeito da enunciação e o sujeito do enunciado nessa dissonância que a negativa exprime.

Diferentemente de Pichon (1928), no entanto, Lacan (1961-62/2003) aponta para as posições em que ne e pas se encontram na frase, explicitando que às partículas negativas pode ser restituído o valor positivo, de modo que as cargas negativa e positiva dos termos acabam se cruzando, de acordo com o modo de construção da estrutura frasal. A partícula pas, portanto, para além de conotar "o puro e simples fato da privação", é vista como "alguma coisa que, longe de ser, em sua origem, a conotação de um buraco, da ausência, exprime ao contrário a redução, o desaparecimento talvez, mas não acabado, deixando atrás dele as marcas do menor traço, o mais evanescente" (Lacan, 1961-62/2003, pp. 121-122). Tratase da ausência que pressupõe a presença; do apagamento que implica a permanência da marca deixada pelo traço, como rasura, como pegada ou passo. Portanto, diz respeito à negação (Verneinung) que supõe a afirmação (Bejahung) na qual se apoia, isto é, afirmação de alguma coisa do real que não está simplesmente suprimida (aufhebt), mas, ao contrário, concerne fundamentalmente ao ser na medida em que é eternizada como traço.

O traço preenche a função do sujeito, que deverá posteriormente receber os atributos que lhe darão suporte. A identificação primordial ao traço unário implica, portanto, o apagamento da consistência implicada na linguagem em torno do ser neonato, deixando o resíduo de um corte vazio, privação desde a qual partirá o sujeito:

A negação nunca é linguisticamente um zero, mas um não um. [...] E toda a história da negação é a história desta consumação por alguma coisa que está onde? É justamente o que tentamos cercar: a função do sujeito como tal. (Lacan, 1961-62/2003, p. 152)

Assim a função do não um confere à casa vazia a notação -1. Por isso, a proposta lacaniana de indicar que a marca conferida pelo traço unário é essencialmente a marca de uma distintividade - Einzigkeit -, e não de uma unificação - Einheit. A distintividade define a função do traço na medida em que é a sua própria possibilidade. É o corte, vazio, ausência que suporta qualquer existência. O sujeito advém, portanto, dessa privação primeira a que se articula a perda primordial do objeto freudiano:

o possível de que se trata aqui não é nada senão o possível do sujeito. Só o sujeito pode ser esse real negativado por um possível que não é real [mas, sim, simbólico]. O -1, constitutivo do ens privativum, nós o vemos assim ligado à estrutura a mais primitiva de nossa experiência do inconsciente, na medida em que ela é aquela, não do interdito, nem do dito que não, mas do não-dito, do ponto onde o sujeito não está mais para dizer se ele não é mais mestre dessa identificação ao 1, ou dessa ausência repentina do 1, que poderia marcá-lo. Aqui se encontra sua força e sua raiz. (Lacan, 1961-62/2003, p. 172)

Lacan (1961-62/2003) nos conduz à noção do sujeito constituído como -1 para tratar das faltas constitutivas do sujeito, retomando o termo pelo qual abordara a ideia de uma exclusão primitiva como instauradora desse vazio de onde parte o sujeito:

E alguns se preocupam que eu não dê lugar à Verwerfung. Ela está lá, antes, mas é impossível partir dela de uma maneira dedutível. Dizer que o sujeito constitui-se primeiramente como -1 é algo onde vocês podem ver efetivamente, como era de se esperar, é como verworfen que nós o vamos encontrar (p. 180).

O traço unário articula-se a essa Verwerfung constitutiva, demarcando o que é da ordem da instauração do registro simbólico organizado pelo encadeamento significante. Entende-se aqui a Ausstossung como implicada na Verwerfung e remontando a algo do real. E é a partir dessa suposição de uma divisão primitiva entre o real e o simbólico, em contraposição a um dentro e um fora proposto por Freud, que Lacan recorrerá à topologia para situar a continuidade entre as instâncias constitutivas do sujeito marcado pelo traço que o funda simbolicamente, franqueando a amarração entre aquilo que se organiza como imaginário e aquilo que o mobiliza sem se escrever, isto é, sem se inserir na lógica das representações [Vorstellungen]: o real.

O sujeito se constitui a partir do traço unário, o que faz com que entre ele e a realidade exista o significante (Lacan, 1962-63/2005, p. 31). O homem apreende o real por um significante. A relação com o Outro é possibilitada pelo significante e a articulação dos significantes faz do mundo uma rede de traços em que a passagem de um ciclo a outro se torna possível: "Isso quer dizer que o significante gera um mundo, o mundo do sujeito falante, cuja característica essencial é que nele é possível enganar” (Lacan, 1962-63/2005, p. 87). O ser humano engana e se engana ao apagar seus traços, seus vestígios,

2 Cf. Damourette, J., \& Pichon, E. (1928). Sur la signification psychologique de la négation en français. In Journal de Psychologie Normale et Pathologique. Paris: Félix Alcan. 
enfim, ao servir-se do significante: "Quando um traço é feito para ser tomado por um falso traço, sabemos que há aí um sujeito falante, sabemos que há aí um sujeito como causa" (Lacan, 1962-63/2005, p. 75). Afinal, os animais não apagam suas pegadas ou deixam falsas pistas.

Podemos constatar que a precocidade com que se dá a inscrição do traço unário não permite que o neonato obtenha dele qualquer significação, de tal maneira que o que fica registrado como "traço mnêmico" são as repetições de certas experiências (cf. Lacan, 1961-62/2003). Lacan (1961-62/2003) compara o traço unário às marcas incrustadas na costela de um cabrito que ele viu em um museu, datada de uma época anterior ao advento da escrita. Nesta costela, por mais que se possa supor que as marcas referiam-se às caçadas, só quem fez as marcas sabe, de fato, o que elas significam. Essas marcas não são significantes e não há como distingui-las: Como saber qual foi a primeira e qual foi a última caçada? O que foi caçado em cada ocasião? Por que, então, registrá-las? Esta última pergunta surge novamente frente ao curioso hábito do Marquês de Sade de entalhar na cabeceira de sua cama seus orgasmos. As marcas dos gozos não são diferenciadas, não passam pelo registro do significante, o que leva Lacan (1961-62/2003) a pensar que o sujeito marca em seu corpo as experiências de satisfação antes mesmo de acumular um saber que lhe permitiria prover tal marca de uma significação.

A associação entre gozo e traço unário ou entre as experiências de satisfação e o significante não é necessariamente de significação e, muitas vezes, jamais é significada, apenas remetendo a outros significantes. Trata-se simplesmente de marcas que se inscrevem no corpo, uma sucessão de Uns, sem nenhum sentido. Essa função do corpo como superfície de entalhe é a novidade a ser explorada por Lacan no Seminário 10, de modo que nos interessa, a partir de agora, esses cavos, esses buracos de gozo sinalizados pelo significante.

\section{O Objeto a não Significantizável e o Significante da Perda do Objeto}

Lacan (1962-63/2005) afirma que "sempre há no corpo, em virtude desse engajamento na dialética significante, algo de separado, algo de sacrificado, algo de inerte, que é a libra de carne" (p. 242). A "libra de carne"3, o objeto que pode ser cedido, cria um espaço de entrelaçamento entre o corpo do sujeito e o corpo do Outro. Os objetos parciais destacados são objetos que o sujeito cedeu a fim de determinar o desejo do Outro. Se ele pode cedê-los, é porque o Outro os deseja (Safatle, 2006, p. 208). E, aqui, vemos que é num ponto de carência do Outro, em seu desejo por algo que lhe falta, que o sujeito busca uma orientação significante. O ponto de onde surge a existência do significante é aquele que, em certo sentido, não pode ser significado: "É o que chamo de ponto falta-de-significante" (Lacan, 1962-63/2005, p. 150). É ali onde toda significância falha, no âmago do desejo do Outro, portanto, no ponto fálico que o objeto $a$ vem tomar seu lugar, participando da natureza do significante.

O objeto $a$ advém de um corte que se dá no corpo. Ele é algo que se separa do sujeito e será buscado no Outro. Lacan (1962-63/2005, p. 36) define o objeto $a$ como o resto da divisão do sujeito pelo Outro: "O $a$ é o que resta de irredutível na operação total do advento do sujeito no lugar do Outro, e é a partir daí que ele assume sua função. [...]. Na medida em que ele é a sobra, por assim dizer, da operação subjetiva, reconhecemos estruturalmente nesse resto, por analogia de cálculo, o objeto perdido" (p. 179). É o próprio Lacan quem indica a analogia entre das Ding 4 , a perda primordial do objeto, e o objeto $a$, o que leva Miller (2005) a constatar que o psicanalista faz da angústia o operador que permite a das Ding tomar forma de pequeno $a$ : "Isso não se encontra com todas as letras no Seminário [10]. A angústia funciona nesse Seminário como um operador que produz o objeto-causa" (p. 54).

O objeto perdido no Seminário 10 toma a forma do a ao se conectar ao corpo e produzir objetos causa de desejo. O objeto perdido nos diferentes níveis da experiência corporal em que se produz seu corte é o que constitui o suporte, o substrato autêntico, de toda e qualquer função da causa (Lacan, 1962-63/2005): "A forma primordial da causa é a causa de um desejo" (p. 321). De acordo com Lacan (1962-63/2005), o objeto $a$ está localizado numa "precessão essencial" em relação ao objeto como objeto do desejo: "Na intencionalidade do desejo, que deve ser distinguida dele, esse objeto deve ser concebido como a causa do desejo. Para retomar minha metáfora de há pouco, o objeto está atrás do desejo" (Lacan, 1962-63/2005, p. 115, itálicos nossos).

Este objeto atrás do desejo pode ser ilustrado pelo apólogo do louva-a-deus ${ }^{5}$, no qual Lacan convoca seus interlocutores a imaginarem uma cena em que um indivíduo, vestindo uma máscara de louva-a-deus, coloca-se diante de um espécime gigante desse inseto. Se este louva-a-deus for uma fêmea, ela pode tomar o sujeito pelo macho cuja cabeça vai devorar, mas não é possível saber de antemão qual o desejo do louva-a-deus. Talvez este desejo só apareça na presença do objeto. O objeto que é colocado na frente depende, assim, daquele que está atrás, prestes a devorar-lhe. $\mathrm{O}$ fato de o mascarado não ser

3 Expressão tomada de empréstimo da obra O Mercador de Veneza (1596/1598), de William Shakespeare.

4 Cf. Lucero, A., \& Vorcaro, A. (2009). Das Ding e o Outro na constituição psíquica. Estilos da Clínica, 14(27), $230-251$.

5 Cf., por exemplo, Lacan, 1960-61, lição de 4/4/1962 - inédito; dentre outras passagens dos Seminários 8 e 9. 
o equivalente do esperado pela fêmea (que poderia não esperar nada) tem menos importância do que ele ter se arriscado ao colocar-se como instrumento para o desejo do Outro. A angústia guardaria relação com esta presença enigmática do desejo do Outro, que irá questionar o sujeito em seu próprio ser de objeto. Afinal, há um perigo constante de ser "devorado", de se tornar apenas o instrumento do gozo, quando o sujeito se torna o objeto do desejo do Outro. Por conseguinte, o sujeito pode oferecer apenas um pedaço de seu corpo para apaziguar o Outro sob o risco de perder-se por inteiro: "Larga-se um pedaço para salvar o que resta" (Soler, 2012, p. 151).

A relação do homem com o desejo depende do despedaçamento do próprio corpo, do corte, de forma que a anatomia, em seu sentido etimológico de corte, é, de fato, o destino (Lacan, 1962-63/2005, p. 259). Sublinhemos que o sujeito cede uma parte de seu corpo, tanto para preservar o que resta dele quanto na expectativa de que algo melhor se apresente. É para proteger a falta que permite a emergência do desejo que o sujeito separa-se dos objetos, angustiando-se frente a essa decisão entre o gozo e o desejo: "a angústia não é a dúvida, a angústia é a causa da dúvida" (Lacan, 1962-63/2005, p. 88). Esta angústia que antecede a perda do objeto é efetivamente um sinal de alerta, o que Freud (1926/1996) já havia antevisto. Na zona que separa o gozo e o desejo, situa-se a angústia (Lacan, 1962-63/2005, p. 201). Nas palavras de Lacan (1962-63/2005):

Vocês não sabem que não é a nostalgia do seio materno que gera a angústia, mas a iminência dele? O que provoca a angústia é tudo aquilo que anuncia, que nos permite entrever que voltaremos ao colo. Não é, ao contrário do que se diz, o ritmo nem a alternância da presença-ausência da mãe. A prova disso é que a criança se compraz em renovar esse jogo de presençaausência. A possibilidade da ausência, eis a segurança da presença. O que há de mais angustiante para a criança é, justamente, quando a relação com base na qual essa possibilidade se institui, pela falta que a transforma em desejo, é perturbada, e ela fica perturbada ao máximo quando não há possibilidade de falta, quando a mãe está o tempo todo nas costas dela, especialmente a lhe limpar a bunda, modelo da demanda, da demanda que não pode falhar (p. 64).

Uma das fórmulas de Lacan (1962-63/2005) para a angústia é de que ela é a falta da falta. A outra, de que a angústia não é sem objeto, é esclarecida por essa passagem na qual verificamos que é na iminência de que um objeto venha a preencher o lugar do desejo que deveria permanecer vazio que surge a angústia. Assim, "não só ela [angústia] não é sem objeto, como também, muito provavelmente, designa o objeto [...] mais profundo, o objeto derradeiro, a Coisa" (Lacan, 1962-63/2005, pp. 338-339). Quando a criança se torna o objeto de desejo da mãe, o lugar da falta, de das Ding, é obliterado e perde-se a referência do significante fálico.

De acordo com Colette Soler (2012), há uma sutil diferença entre o objeto perdido, separado do corpo, e o objeto cedível, que o sujeito "larga", se desprende, na espera de um substituto. Enquanto o primeiro seria pré-subjetivo, isto é, anterior ao próprio sujeito, o segundo "é um momento constitutivo da representação do sujeito pelo objeto ou sua equivalência [...] ao objeto" (Soler, 2012, p. 148). O objeto perdido é das Ding. Ele é um limite pressuposto pela ação mesma do significante (Safatle, 2006, p. 158). O objeto é perdido desde a entrada no mundo simbólico, no nascimento e no grito que se desprende e será interpretado pelo Outro como apelo. Já o objeto cedido é identificado pelo sujeito como veículo de gozo e como parte desejada pelo Outro na medida em que também lhe falta. O Outro não tem o objeto e demanda ao sujeito que aceite o objeto ofertado, que se deixe enganar pelo significante. Duas faltas se recobrem. A cessão se manifesta nos fenômenos, na alimentação ou excreção, quando o objeto é arrancado da carne. O objeto $a$ oral, anal, escópico e vocal possui substância, materialidade. O objeto $a$ é real, simbólico e imaginário. Assim, para contemplar os três registros do funcionamento psíquico, a significação fálica deve fazer sua incidência, antes mesmo do Nome-do-Pai e da metáfora paterna.

O falo é o significante que servirá de referência para o desejo e para a relação com o corpo: "às particularidades anatômicas de que se trata no homem, se junta sempre o efeito de um significante cuja transcendência, por conseguinte, é evidente em relação ao citado desenvolvimento" (Lacan, 1962-63/2005, p. 354). O falo exerce sua função em todos os níveis da relação com o objeto $a$ - oral, anal, escópico e invocante -, pois a relação com o corpo é atravessada pelo gozo que, por sua vez, está apenso ao Outro. Ao significar a perda do objeto, o falo remete a uma ordem simbólica que vale para todos que partilham um mesmo sistema linguístico:

Examinemos, portanto, os efeitos dessa presença [do significante fálico]. Eles são, para começar, os de um desvio das necessidades do homem pelo fato de ele falar, no sentido de que, por mais que suas necessidades estejam sujeitas à demanda, elas lhe retornam alienadas. Isso não é efeito de sua dependência real [...], mas da configuração significante como tal e de ser do lugar do Outro que sua mensagem é emitida. (Lacan, 1958/1998, p. 697)

O objeto que passa pelo Outro retorna como um objeto sexualizado, investido libidinalmente, pronto para desenhar os orifícios do corpo. Dessa maneira, o objeto jamais pode ser o equivalente de uma função natural que satisfaria as exigências instintuais, até porque tal naturalidade já foi subvertida no próprio sujeito que demanda. No máximo, o sujeito recebe do 
Outro o contorno de suas zonas erógenas, que para sempre servirão como pontos de fixação da libido, isto é, fontes de gozo. Porém, os objetos e as maneiras de servir-se desse corpo não podem ser previamente determinados.

A extração corporal do objeto $a$ ocorre muito precocemente e independe da intervenção da metáfora paterna: "O pai não é a causa da separação dos objetos da pulsão parcial nem da castração no nível sexual. É o Outro da linguagem, é o fato de entrar na linguagem" (Soler, 2012, p. 159). O significante fálico é o que vem recobrir a perda oriunda da entrada na linguagem. O falo

é aqui esclarecido por sua função. Na doutrina freudiana, o falo não é uma fantasia, caso se deva entender por isso um efeito imaginário. Tampouco é, como tal, um objeto (parcial, interno, bom, mau etc.), na medida em que esse termo tende a prezar a realidade implicada numa relação. E é menos ainda o órgão, pênis ou clitóris, que ele simboliza. [...] Pois o falo é um significante. (Lacan, 1958/1998, pp. 696-697, itálicos nossos)

O falo é o significante da perda do objeto. O objeto $a$ é causa de desejo, pois situa-se num tempo lógico anterior à assimilação significante que organiza o desejo, resistindo, assim, a qualquer tentativa de "significantização". O que pode parecer paradoxal aqui é que esta operação só é possível pela existência do significante, porque habitamos num mundo de linguagem. Isso que é impossível de ser simbolizado é efetivamente o que caracteriza o Real na teoria lacaniana, de modo que "neste seminário [Seminário 10], com efeito, que Lacan situa o status real do objeto a" (Quinet, 2012, p. 13). Após o Seminário 10, a noção de pai se vincula a uma condição complementar à causa e à operação da linguagem (Soler, 2012, pp. 162-164). É o seu desejo que pode estruturar a causa e situar um objeto para o sujeito. O objeto $a$ é anônimo, sem nome, e caberá ao pai dar uma filiação, uma história a esse objeto. Para que o objeto entre no âmbito da partilha, é preciso uma segunda subtração de gozo, relacionada à inscrição do Nome-do-Pai, que possibilita o surgimento de um terceiro tipo de objeto $a$. O objeto $a$ historiado, conforme Soler (2012), é diferente do objeto que o causa: o objeto causa é a condição para o desejo, mas o objeto visado pelo desejo depende da fantasia. O objeto $a$, causa do desejo, se refere às pulsões dispersas em sua satisfação, não integradas na imagem especular. Esses objetos pulsionais que visam apenas ao gozo coexistem independentemente de qualquer organização ou cronologia. Eles não são socializados, partilháveis pela cultura; são objetos que servem à satisfação, ao gozo.

Lacan (1962-63/2005) alude a uma desordem dos pequenos $a$, ainda não unificados na Gestalt [forma] do corpo: "com efeito, são objetos anteriores à constituição do status do objeto comum, comunicável, socializado. Eis do que se trata no $a$ " (p. 103). E, nesse sentido, "nenhum falo permanente, nenhum falo onipotente é próprio por natureza para fechar, seja pelo que for de apaziguador, a dialética da relação do sujeito com o Outro e com o real” (Lacan, 1962-63/2005, p. 262, itálico nosso).

\section{A Irredutibilidade do Objeto}

Nenhum significante, nem mesmo o fálico, pode fechar a relação do sujeito com o Outro e com o real. O significante não pode nos dar nenhuma garantia justamente porque ele pode nos enganar. Apenas a angústia não engana, de modo que é na angústia suscitada pelo objeto que o sujeito encontra a certeza do gozo: "o gozo não conhece o Outro senão através desse resto, $a$ " (Lacan, 1962-63/2005, p. 192).

A existência do gozo do Outro, o fato incontestável de que o Outro goza é o que atesta para o sujeito a presença do objeto e suscita a angústia. De acordo com Mille (2005, p. 43), a relação do sujeito com o Outro é fundada no gozo, a tal ponto que poderíamos colocá-lo como a garantia da ordem significante. Afinal: "O que pode assegurar uma relação do sujeito com esse universo de significações senão que, em algum lugar, existe gozo?” (Lacan, 1962-63/2005, p. 56). O gozo está situado no corpo; é sempre o corpo que goza e que permitirá ao significante encarnar-se: "o homem que fala, o sujeito, a partir do momento em que fala, já está implicado por essa fala em seu corpo" (Lacan, 1962-63/2005, p. 241).

Acreditamos que a não cessão do objeto $a$, que permitiria perscrutar o gozo do Outro, está relacionada à ausência de enunciação no sujeito autista. Essa hipótese, explorada por Maleval (2009) em relação ao objeto voz, tem como contraponto uma presença marcante dos objetos na vida dos autistas:

Objetos que não mudam de aparência e posição, que conversam sua mesmice e nunca ameaçam interferir na solidão da criança, são prontamente aceitos pela criança autista. Ela tem uma boa relação com objetos; interessa-se por eles, pode brincar com os mesmos por horas seguidas. (Kanner, 1943, s.p.)

Lacan (1964/1979) nota que não apenas os autistas, mas o lactente se interessa por tudo o que entra em seu campo de percepção; em especial, os objetos: "que haja objetos desde o tempo mais precoce da fase neonatal é o de que não há a menor dúvida. Autoerotisch [autoerótico] não pode absolutamente ter o sentido de desinteresse em relação a eles” (p. 180). Pois bem, os objetos se fazem notar desde os primeiros tempos da constituição subjetiva e coexistem com uma determinada 
forma de autoerotismo. Ainda Lacan (1962-63/2005, p. 55) afirma que, na dimensão autoerótica, temos um sujeito do gozo, bem como um gozo autista, atinente a todo tipo de investimento libidinal no próprio corpo, sem a necessidade de que este corpo seja reconhecido como distinto do meio. Portanto, não se trata de uma imagem do corpo já constituída, diferenciada, sobre a qual instaura-se o narcisismo, mas de um corpo-carne, ainda não delimitado pelos significantes ou pelo recurso ao imaginário. $\mathrm{O}$ objeto adquire um papel essencial nessa mudança de perspectiva em relação ao corpo por permitir uma articulação entre corpo e linguagem que nem sempre vem acompanhada de representação ou simbolização.

Continuando a perspectiva do interesse pelos objetos ressaltada em 1964, Lacan (1964/1979) remete-se a Freud para distinguir entre a estrutura do amor daquela da pulsão. O quadro do narcisismo é feito da inserção do autoerotismo nos interesses organizados do eu, já existindo ali representação dos objetos, escolha e discernimento. Essas são falsas pulsões (ditas de autoconservação). O amar-se através do outro não deixa, no campo narcísico do objeto, nenhuma transcendência ao objeto incluído, pois nada representa aí o Outro radical. O sujeito só atinge a dimensão do Outro por meio da pulsão. A articulação do vaivém pulsional circular, mas não recíproco, mantém uma hiância que exige a atividade do se fazer em que a pulsão se encarrega de ir buscar algo que responda no Outro. Para Lacan (1964/1979), ao distinguir os dois campos, de um lado, o campo pulsional, e, de outro, o campo narcísico do amor, Freud articula no amor a reciprocidade amar e ser amado, enquanto na pulsão trata-se de pura atividade, em que mesmo a fase passiva exige trabalho colossal.

Acompanhando o trabalho de Marie-Christine Laznik com bebês com risco de autismo, deparamo-nos com o interesse ativo pelos objetos e mesmo com a existência do apontar imperativo, quando a criança quer alguma coisa. Porém, não há o movimento de inclusão do Outro nessas atividades, como verificamos na ausência do olhar e/ou da fala, e no apontamento de objetos não partilháveis, normalmente, comida ou um brinquedo a ser segurado. A hipótese de que o autista não atinge o terceiro tempo do circuito pulsional (reflexivo), não oferecendo seu corpo para o outro, fundamenta-se na observação de que, nesses casos, o movimento da pulsão se faz unicamente em vaivém: ir em direção a algo e voltar para o corpo ou para um objeto que tem função de pedaço de corpo (Laznik, 2011, p. 18). Nesse sentido, muitas das intervenções de Laznik nas sessões junto com a mãe e o bebê consistem em fazer o gozo surgir no campo do Outro, de modo que o bebê se sinta provocado por essa relação. Assim, Laznik brinca com as mães, suas co-terapeutas, que também têm a oportunidade de redescobrir o prazer e o gozo de estar com seus bebês, por vezes demasiado fechados em si mesmos, a ponto de terem desencorajado as tentativas de interação. Vejamos um pequeno fragmento.

Marina, bebê de quatro meses, gosta de chupar suas mãos. Sua mãe, muito atenta a tudo que interessa a filha, ajudalhe a reter suas mãozinhas junto da boca. De repente, Marina se põe a sugar o dedo de sua mãe com um prazer evidente e Laznik (2009) fala no lugar de Marina:

"Hum! Como é bom o dedo de minha mamãe! É gostoso!" Marina o suga ainda com mais vontade. A mãe: "Mas se ela gosta tanto disto, será preciso lhe oferecer um pirulito". Eu falo ainda no lugar de Marina: "Mas, mamãe, é do seu dedo que eu gosto! É tudo de bom o dedo da mamãe!” A mãe: “Ah! Sim, é verdade, os pirulitos ainda não são para sua idade". Eu me volto, então, para a mãe, para lhe mostrar quanto ela, Marina, gosta do dedo de sua mãe, que é bom como um pirulito. Num tom confidencial, a mãe me diz: "Eu vou lhe confessar, eu também acho o dedinho de Marina bom como um docinho". No mesmo tom confidencial, eu pergunto: "E o pezinho?". A mãe, cuja filha sempre chupa o dedo, confessa com um cacarejo de prazer: "E às vezes até mesmo a barriguinha!". A voz da mãe que revela seu prazer é envolvente; Marina olhando para ela se põe a vocalizar com todas suas forças: "Guo, te, re te". (pp. 64-65)

O reconhecimento de Marina como fonte de prazer para a mãe produz uma modificação na prosódia materna que invoca o bebê a entrar numa "conversação". Nesse jogo é o corpo de Marina que se fragmenta em objetos de satisfação, bem como o dedo de sua mãe que, um dia, poderá a vir substituído por um pirulito. Para Laznik (2009), a introdução do terceiro tempo do circuito pulsional produz uma nova dinâmica entre esse bebê e sua mãe, que precisará ser repetida muitas vezes até que a criança saia de seu fechamento autístico. Assim, aos 15 meses, Marina é capaz de comer um iogurte sem olhar para sua mãe, apenas abrindo a boca para receber as colheradas, indiferente à conversa da mãe com a analista ou às interpelações que lhe são feitas. Então, a analista resolve comer "com vontade" uma colherada do iogurte, exclamando o quanto ele é gostoso, "de baunilha", e se surpreende com o olhar de Marina. A mãe tenta obter o mesmo olhar, repetindo o jogo da analista, mas não recebe nada em troca. Sensível a essa situação, a analista dá uma colherada de iogurte para a mãe, o que a surpreende e diverte. Marina olha uma e outra, ri e aproxima os braços ritmicamente, como se quisesse bater palmas. Laznik (2014) nota que é o prazer da mãe que captura Marina, uma vez que ela volta a abaixar os olhos quando tem que comer seu iogurte. Não é o alimento que interessa, mas a pulsão oral, a prosódia alternada entre surpresa e prazer, que envolve também a voz e a pulsão invocante. Voltaremos a esse ponto após outro exemplo clínico.

No relato do caso de Marie-Françoise, uma criança autista de dois anos e meio com dificuldades para alimentar-se, Rosine Lefort (2003) observa que o objeto serve para tampar os furos do corpo da criança. Na situação em que Marie- 
Françoise fracassa em dar comida a um bebê de brinquedo, ela serve-se de um marinheiro de plástico para colocar em frente aos olhos, o que a analista interpreta como um deslocamento do furo da boca para os olhos, fechados pelo marinheiro, seu "duplo". Quando o bebê cai no prato de arroz com leite, Marie-Françoise coloca a cabeça do bebê na boca, olha para a analista, mas não faz nenhum movimento de sucção. Agora é a boca que se fecha, sem que nenhum alimento seja ingerido.

Lefort (2003, p. 37) conclui que o bebê, assim como o marinheiro, evita que uma demanda seja endereçada à analista e, logo que possível, livra-se desses objetos. Rosine busca em uma relação corporal com a criança uma orientação para o tratamento, deixando que ela pegue seus óculos, explore sua boca com as mãos ou seu corpo com a baba. Mesmo constatando uma dificuldade do autista em extrair um objeto do corpo do Outro para obturar o furo de seu próprio corpo - pois, na ausência de uma capacidade de simbolização, isso poderia efetivamente deixar o Outro furado -, Rosine joga com seu corpo. Isso tem o seguinte desfecho: "Ao invés de fazer a passagem dos objetos em direção ao corpo do Outro, ela [MarieFrançoise] se fecha completamente em sua relação com os objetos, em oposição a mim, e ela termina a sessão me dando uma sonora bofetada" (Lefort, 2003, p. 36, tradução nossa ${ }^{6}$ ).

Ao invés de servir-se dos objetos, Rosine tenta uma interação direta com a criança. Já Laznik - ciente de seu papel de terceiro na relação mãe-bebê, ainda que, por vezes, ocupe uma posição materna (o que aconteceu no episódio de dar iogurte para a mãe de Marina) - parte das situações que são encenadas para fazer surgir o objeto do desejo. Que esse objeto seja o corpo de Marina ou o iogurte não tem importância, desde que o prazer emerja nessa relação. Através do objeto inúmeras situações são criadas e a criança pode ser surpreendida de diferentes maneiras, sem que a presença do Outro se torne invasiva.

É célebre a formulação lacaniana do desejo como desejo do Outro, de modo que sentir a presença do desejo pode mobilizar alguma posição subjetiva, como vimos no exemplo do louva-deus. $\mathrm{O}$ autismo evidencia que a cessão do objeto - dessa parte de carne e de gozo - não é algo natural, de modo que é possível permanecer fechado e angustiado na presença do Outro, sem jamais consentir aos efeitos de uma perda. Porém, as marcas da linguagem inevitavelmente deixam rastros e a aposta é de que alguma construção subjetiva seja possível, mesmo que isso implique outras modalidades de relação de objeto e de subjetivação.

De imediato, parece-nos que, quando a angústia imobiliza o movimento em direção ao Outro, é preciso manejar a perda do objeto de forma a retomar o curso da estruturação subjetiva. Mas de que objeto se trata no autismo? Como conceber a perda da voz ou do olhar se não em situações que coloquem em jogo esses objetos? Seria possível pensar em uma função para os objetos eleitos pelos autistas, ou de sua preferência, que favorecesse uma cessão do objeto e reabrisse o circuito pulsional em direção ao Outro? Qual o critério de eleição desses objetos? Poderíamos atribuir-lhes algum valor significante?

Oscilamos entre conceber um corpo furado (Lefort, 2003), perdido, e um corpo fechado, uma carapaça, como diriam os psicanalistas da tradição inglesa. Quando a perda não é simbolizada ou o objeto não pode ser cedido, mas é simplesmente largado - como uma "casca", para fazermos uma referência ao comentário lacaniano sobre o corpo de Joyce - como recompor esse corpo? Seria um corpo marcado, "roxo", sensível, que não pôde ser tratado pelo significante? Feridas abertas, células mortas, em que se esvaem as trilhas por onde passaria a seiva/significante? Como pensar a hipersensibilidade dos autistas a determinados estímulos, seu vínculo a alguns objetos e a ideia freudiana do Projeto (Freud, 1895/1995) da construção de caminhos por onde deve escoar a excitação? Essas questões, bem como o manejo clínico através do objeto estão em jogo na pesquisa "O uso de objetos na direção do tratamento psicanalítico da criança autista", desenvolvida na Universidade Federal do Espírito Santo, com o apoio da FAPES/CAPES, em que discutiremos se o tratamento do gozo é possível e até que ponto ele permite uma (re)estruturação do sujeito ou uma nova estrutura.

$\overline{6} \quad$ No original: "Au lieu de faire le pas des objets vers le corps de l'Autre, elle s'enferme tout à fait dans ses rapports aux objets, en opposition à moi, et elle termine la séance en me donnant une gifle retentissante" (Lefort, 2003, p. 36). 


\section{Referências}

Damourette, J., \& Pichon, E. (1928). Sur la signification psychologique de la négation en français. In Journal de Psychologie Normale et Pathologique. Paris: Félix Alcan.

Defoe, D. (2009). Robinson Crusoé. Rio de Janeiro: BestBolso.

Dicionário Houaiss da língua portuguesa. (2009). Rio de Janeiro: Houaiss/Objetiva.

Freud, S. (1995). Projeto de uma psicologia (O. Gabbi Jr., trad.). Rio de Janeiro: Imago. (Originalmente publicado em 1895)

Freud, S. (1996). Inibição, sintoma e angústia. In J. Strachey (Ed.), Edição Standard Brasileira das Obras Psicológicas Completas de Sigmund Freud (Vol. 20). Rio de Janeiro: Imago. (Originalmente publicado em 1926)

Freud, S. (2007). A Negativa. In S. Freud, Escritos sobre a psicologia do inconsciente (Vol. 3, L. Hanns, trad.). Rio de Janeiro: Imago. (Originalmente publicado em 1925)

Kanner, L. (1943). Os distúrbios autísticos do contato afetivo. (Link).

Lacan, J. (1979). O Seminário, livro 11: os quatro conceitos fundamentais da psicanálise (1964). Rio de Janeiro: Jorge Zahar.

Lacan, J. (1992). O Seminário, livro 8: a transferência (1960-61). Rio de Janeiro: Jorge Zahar.

Lacan, J. (1998). A significação do falo. In Escritos. Rio de Janeiro: Jorge Zahar Editor. (Originalmente publicado em 1958)

Lacan, J. (2003). O Seminário, livro 9: a identificação (1961-62). Recife: Centro de Estudos Freudianos do Recife.

Lacan, J. (2005). O Seminário, livro 10: a angústia (1962-63). Rio de Janeiro: Jorge Zahar.

Le Petit Robert. (2014). Paris: Le Robert.

Laznik, M.-C. (2009). Bebê com risco de autismo em tratamento conjunto: visa-se a reversibilidade total? Reverso, 31(58), 63-74. (Link)

Laznik, M.-C. (2011). Rumo à fala: três crianças autistas em psicanálise. Rio de Janeiro: Companhia de Freud.

Laznik, M.-C. (2014). Empathie émotionnelle et autisme. In M. D. Amy (Dir.), Autismes et psychanalyses. Toulouse: Érès.

Lefort, R., \& Lefort, R. (2003). La distinction de l'autisme. Paris: Seuil.

Lucero, A., \& Vorcaro, A. (2009). Das Ding e o Outro na constituição psíquica. Estilos da Clínica, 14(27), 230-251. (Link)

Maleval, J.-C. (2009). L'autiste et sa voix. Paris: Champ Freudian.

Miller, J. A. (2005). Introdução à leitura do Seminário da Angústia de Jacques Lacan. Opção Lacaniana, (43), 7-81. São Paulo: Eólia.

Quinet, A. (2012). Apresentação. In C. Soler, Seminário de leitura de texto ano 2006-2007 (Coleção Pathos). São Paulo: Escuta.

Safatle, V. (2006) A paixão do negativo - Lacan e a dialética. São Paulo: Unesp.

Silveira, D. M. G., \& Vorcaro, A. (2016). Da Verneinung ao traço unário. Ágora, 19(3), 499-532. (Link) 
Soler, C. (2012). Seminário de leitura de texto ano 2006-2007 (Coleção Pathos). São Paulo: Escuta.

\section{Endereço para correspondência}

Ariana Lucero

End.: Rua Constante Sodré, 1234/102 Praia do Canto CEP: 29055-420 Vitória - ES

Email: luceroariana@yahoo.com.br

Angela Vorcaro

End.: Rua Paul Bouthilier, 353. Mangabeiras CEP: 30315-010 Belo Horizonte - MG

Email: angelavorcaro@uol.com.br 